\title{
Reactive microencapsulation of carbon allotropes in polyamide shell-core structures and their transformation in hybrid composites with tailored electrical properties
}

\author{
F. Oliveira ${ }^{1}$, N. Dencheva ${ }^{1}$, P. Martins ${ }^{2}$, S. Lanceros-Méndez ${ }^{2}$, Z. Denchev ${ }^{1 *}$ \\ ${ }^{1} \mathrm{i} 3 \mathrm{~N}$ - Institute for Polymers and Composites, University of Minho, 4800-058 Guimarães, Portugal \\ ${ }^{2}$ Center/Department of Physics, University of Minho, 4710-057 Braga, Portugal
}

Received 14 July 2015; accepted in revised form 21 September 2015

\begin{abstract}
Polyamide 6 microcapsules (PAMC) loaded with 2-10 wt $\%$ of different carbon allotropes: carbon black, multiwalled carbon nanotubes, carbon nanofibers and graphite were synthesized via activated anionic polymerization (AAROP) of $\varepsilon$-caprolactam in solution performed in the presence of the respective micro- or nanosized loads. The forming high-molecular weight microporous PAMC showed typical diameters of $15-35 \mu \mathrm{m}$, the filler particles being entrapped in the core as proven by microscopy methods. The melt processing of the loaded microcapsules produced PA6/C-filler hybrid thermoplastic composites with homogeneous distribution of one or two C-fillers even at loads of up to $10 \%$ without any functionalization. The crystalline structure of all PAMC and molded composites was studied by thermal and X-ray diffraction methods focusing on possible structure modification during the transition from PAMC to molded plates. Mechanical tests in tension and electrical conductivity measurements showed that transforming loaded PAMC into composites by melt processing could be a facile and rapid method to fabricate polyamide composites with improved mechanical performance and tailored electrical and dielectric properties.
\end{abstract}

Keywords: tailor-made polymers, polymer composites, activated anionic polymerization, microcapsules, carbon allotropes

\section{Introduction}

Due to the huge increase of the use of polymer materials in electronics, automotive and aerospace industries, the demand for thermoplastic polymers with dissipative or conductive properties is constantly growing. The necessary enhancement of electric conductivity can be achieved in two ways: (i) by using inherently conductive polymers or (ii) by adding electrical conductive fillers to an insulating polymer matrix [1]. In the first approach, polymers with conjugated $\pi$-electron system e.g., polyaniline, polypyrrole or polythiophene are among those widely used, for example, in organic solar cells as transparent electrical conductive polymer films [2]. The main shortcomings of the inherently conductive poly- mers are their high prices and the difficulties in their melt processing due to non-meltability combined with degradation and poor long-term stability.

In the second approach, conductive fillers are dispersed in a polymer matrix, the most frequently employed being those based on $\mathrm{sp}^{2}$-carbon, e.g., carbon black (CB), carbon nanofibres (CNF), and carbon nanotubes (CNT) [3], as well as exfoliated graphite (GR), graphene, fullerenes and their derivatives [4]. All these carbon materials differ significantly in the shape and morphology of their primary particles: from nanometer-size spheres (for $\mathrm{CB}$ and fullerenes), through medium-to-high aspect ratio tubes with diameters of several nanometers (CNF, CNT), to stacks of graphene sheets with different

\footnotetext{
*Corresponding author, e-mail: denchev@dep.uminho.pt (C) BME-PT
} 
degrees of exfoliation (GR, graphite oxide, functionalized graphene). Due to the strong van der Waals interactions between the single spheres, tubes or sheets, formation of agglomerates is very common for those carbon fillers. Thus, it is difficult to disperse them in polymer matrices by means of conventional melt-processing techniques, affecting negatively the mechanical and conductive properties of the final composite article. Dispersion can be enhanced by surface modification, covalent or noncovalent functionalization of the carbon filler [5-7]. Such treatments result in better adhesion of the filler to the host polymer [8], however they often create surface defects on the filler particles' surface and decrease their inherent conductivity $[9,10]$. The relatively complex chemistry and/or costly reagents of most functionalization procedures additionally impede a cost-effective scale-up to industrial production of the CNT-containing composites and limit their use for high price applications only [3].

A number of polymers have been tested as matrices for carbon allotrope/ thermoplastic hybrid composites, including polyamides, polyesters, aromatic polyethers, and polyolefins [11]. Among them, aliphatic polyamides are quite frequently employed since they possess a unique balance between price, processability, chemical properties and mechanical resistance. Thus, polyamide 6 (PA6), polyamide 12 (PA12) and polyamide 6.6 (PA66) have been melt-mixed with different grades of CNT for studying the structure, morphology, mechanical and electrical properties of the resulting hybrid composites [3, 12-20]. It seems that the extremely high stiffness, electrical and thermal conductivity combined with their high aspect ratio makes CNT suitable fillers for conductive polyamide nanocomposites with prospective applications in electronics, packaging and automotive industries. Polyamide-CB composites have also been prepared and studied [21-23]. CB powders are much cheaper than CNT which is important for industrial applications, however their percolation thresholds are significantly higher $-0.7-2.1 \mathrm{wt} \%$ for CNT against $4.3 \mathrm{wt} \%$ for $\mathrm{CB}$ introduced into PA12 matrix [24]. Exfoliated GR-containing polyamides have been prepared and investigated predominantly in terms of increasing the mechanical properties [25] or thermal diffusivity [26] of the matrix material, whereby the larger the GR stacks size and their exfoliation ratio, the more effective the formation of 3dimensional conductive pathways and high thermal diffusivity. A clear trend toward GR filler chemical modification is observed mainly by oxidation and polymer grafting in order to increase the miscibility with the polyamide matrix $[27,28]$.

In all the polyamide/carbon allotrope composites mentioned so far melt mixing was used as dispersion method, whereby frequently the reported percolation thresholds in CNT-modified hybrids were found to be much higher than the theoretical ones [15]. Studies on shaping of PA6/CNT composites by injection molding revealed that high conductivity values (measured both in-line and in the finished part) can only be achieved at maximum melt temperature and minimum injection speed [29]. These findings together with the necessity of functionalization could be limiting factors for the large scale use of carbon allotrope conductive fillers in thermoplastic PA6 composites.

An alternative to overcome the limitations related to melt compounding would be to synthesize the polymer matrix in-situ, i.e., by initially mixing the filler with the monomer and then polymerizing this system. Such reactive processing in the case of polyamides can be achieved by either hydrolytic or activated anionic ring-opening polymerization (AAROP) of lactams. Thus, O'Neill et al. [30] studied the effect on the in-situ hydrolytic polymerization of $\varepsilon$-caprolactam (ECL) on the structure and properties of GR oxide and found that the separate graphene sheets may be grafted with PA6 chains propagating from their surface, hence increasing the matrix-filler miscibility. No data on the electrical conductivity were presented. Kelar [31] performed AAROP of ECL containing up to $0.3 \mathrm{wt} \%$ of a $\mathrm{C}_{60} / \mathrm{C}_{70}$ fullerene mixture proving that fullerenes do not inhibit the polymerization to PA6. Zuev and Ivanova [32] studied the effect of various fulleroid fillers $\left(\mathrm{C}_{60}\right.$, mixture of $\mathrm{C}_{60} / \mathrm{C}_{70}$ and fulleroid soot) on the mechanical, tribological and electrical properties of PA6-based nanocomposites prepared by in-situ AAROP. Both tensile modulus and strength of the polymer nanocomposites were found to improve with up to $15 \%$ upon the addition of $0.001-0.1 \mathrm{wt} \%$ of fulleroid materials. Electrical volume resistivity decreased with filler loading reaching about $10^{7} \Omega \cdot \mathrm{cm}$ at $0.1 \mathrm{wt} \%$ load. Functionalized $\mathrm{C}_{60}$ fullerene introduced in concentrations of up to $3 \mathrm{wt} \%$ in PA6 matrix by AAROP produced similar volume resistivity values and presented strong evidence for grafting of polyamide links onto the $\mathrm{C}_{60}$ sphere leading to extensive cross- 
linking [33]. The effect of $\mathrm{C}_{60}$ on the mechanical and dielectric properties of nanocomposites based on PA12, prepared by in-situ AAROP has also been studied $[34,35]$.

A common limitation of the bulk AAROP process carried out in solid state is that no mixing is possible at the final stages of the process which results in a gradient of the filler, if the AAROP is not fast enough [33]. Therefore, all issues of the melt-processing techniques and the necessity of fillers' functionalization, although in a lesser extent, are still present. Recently, a possible solution of these problems in PA6 hybrid composites was found by means of AAROP in solution. The process can be carried out in a way to produce micro- or nanosized capsules whose polyamide core entraps well-dispersed filler particles. The loaded capsules are further subjected to melt-processing to shape the final composite [36, 37]. This novel method is characterized by short polymerization times of ca. $60 \mathrm{~min}$, low polymerization temperatures $\left(\sim 135^{\circ} \mathrm{C}\right)$ and up to $75 \%$ conversion to high molecular weight polyamide microcapsules (PAMC). It can introduce up to $30 \%$ of load into the PAMC without any functionalization and is suitable for scale-up to industrial production.
The present work reports on the in-situ synthesis of PAMC loaded with $\mathrm{CB}, \mathrm{CNT}$, GR, CNF or mixtures of them by AAROP in solution. The effect of the content and type of the filler on the structure, morphology and thermal properties of the loaded PAMC is assessed. After transforming PAMC into PA6 hybrids by compression molding, the electrical conductivity and mechanical properties were evaluated as a function of composition, structure and preparation conditions.

\section{Experimental}

\subsection{Materials and preparation}

The ECL monomer with reduced moisture content for AAROP (AP-Nylon ${ }^{\circledR}$ caprolactam) was delivered from Brüggermann Chemical, Germany. Before use, it was kept under vacuum for $1 \mathrm{~h}$ at $23^{\circ} \mathrm{C}$. As polymerization activator, Bruggolen $\mathrm{C} 20^{\circledR}$ from Brüggermann Chemical, Germany (C20) was used. According to the manufacturer, it contains $80 \mathrm{wt} \%$ of blocked di-isocyanate in ECL. The supposed chemical structure of C20 is presented in Figure 1. The initiator sodium dicaprolactamato-bis-(2-methoxyethoxo)aluminate (Dilactamate ${ }^{\circledR}, \mathrm{DL}$ ) was purchased from Katchem, Czech Republic, and used without further

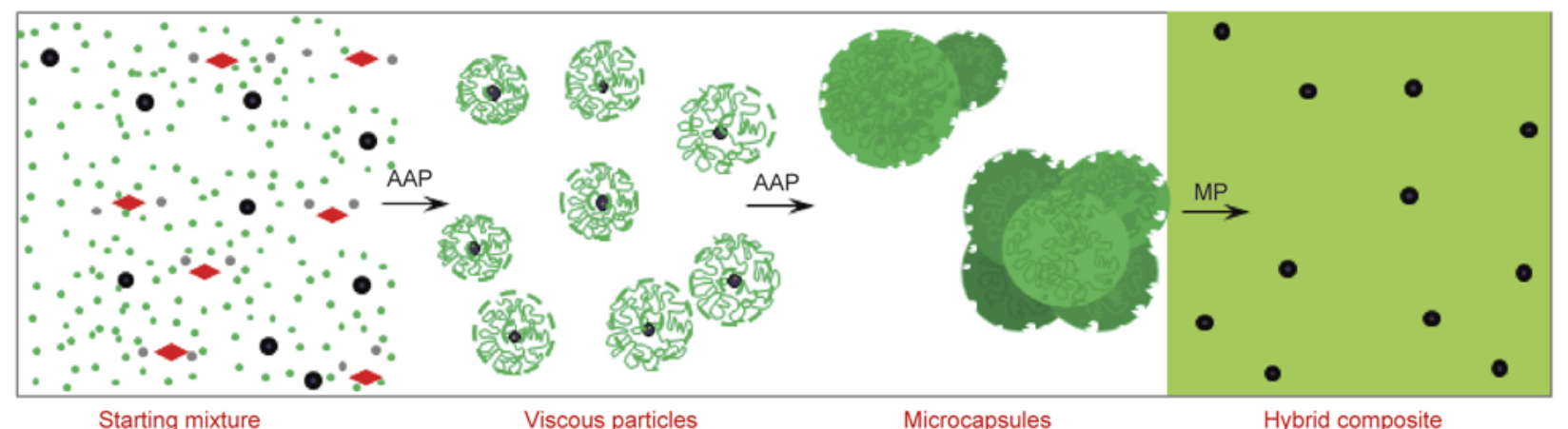

Starting mixture Viscous particles Microcapsules Hybrid composite

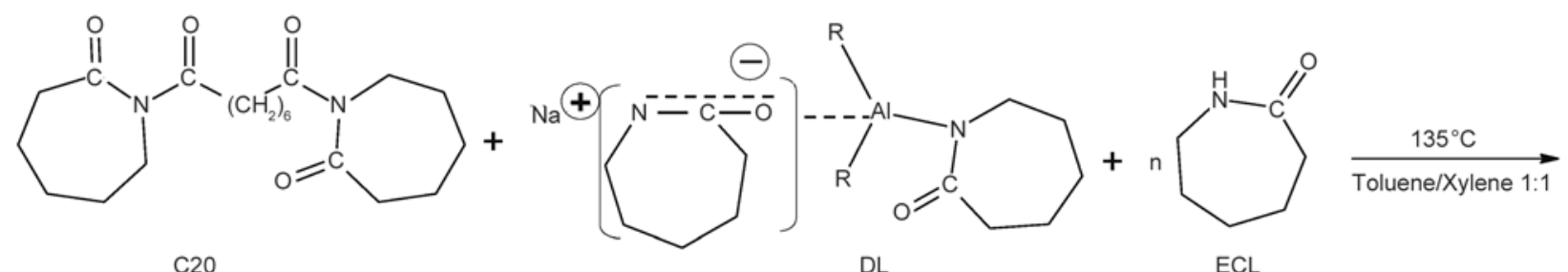

$\mathrm{C} 20$

DL

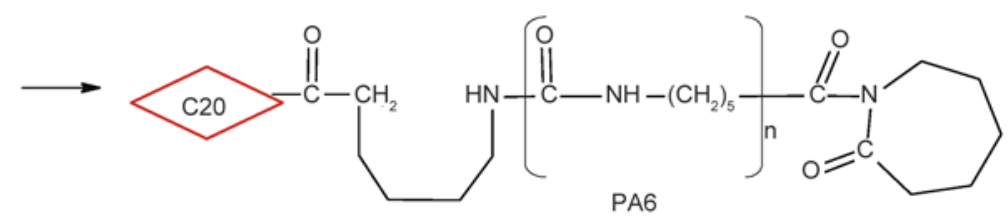

Figure 1. Chemical reactions occurring during AAP: C20 - Bruggolen C20 (activator) $>$; DL - dicaprolactamato-bis-(2methoxyethoxo)-aluminate, $\mathrm{R}=\mathrm{OCH}_{2} \mathrm{CH}_{2} \mathrm{OCH}_{3}$ (initiator); $\mathrm{ECL}-\varepsilon$-caprolactam •; PA6 - anionic polyamide 6; Carbon allotrope powder component $\bullet$; AAP $=$ activated anionic polymerization; $\mathrm{MP}=$ melt processing $(\mathrm{com}-$ pression molding) 
treatment. The multi-walled CNT and GR powder (platelet size $<1 \mu \mathrm{m}$ ) were purchased from Sigma Aldrich; the acetylene CB is a product of S.E.A. Tudor, Spain and the CNF were purchased from Grupo Antolin, Spain. Methanol and other solvents are of 'puriss' grade purchased from Sigma-Aldrich and were used as received.

The AAROP was carried out in a $250 \mathrm{~mL}$ glass flask fitted with thermometer, magnetic stirrer, a DeanStark attachment for azeotropic distillation with reflux condenser, and inlet for dry nitrogen. In a typical synthesis, about $0.5 \mathrm{~mol}$ of ECL and the desired amount of each carbon allotrope $(2,6$ or $10 \mathrm{wt} \%$ in respect to ECL) were added to $100 \mathrm{~mL}$ of 1:1 toluene/ xylene mixture while stirring, under nitrogen atmosphere refluxing the reaction mixture for $10-15 \mathrm{~min}$. Subsequently, $3 \mathrm{~mol} \%$ of DL and $1.5 \mathrm{~mol} \%$ of C20 were added at once. The reaction time was always 1 hour (from the point of catalytic system addition), the temperature being maintained in the $125-135^{\circ} \mathrm{C}$ range at a constant stirring of ca. $800 \mathrm{rpm}$. The carbon-loaded PAMC formed as fine dark grey powder and were separated from the reaction mixture by hot vacuum filtration, washed several times with methanol and dried for $30 \mathrm{~min}$ at $100^{\circ} \mathrm{C}$ in a vacuum oven. After 1 hour of polymerization the yields of PA6 in respect to ECL were 56\% (empty PA6 microcapsules) and $44-60 \%$ for the loaded PAMC (Table 1).

Compression molding of PAMC to plates was performed in a 25 ton Moore hydraulic hot press, Eng- land using a rectangular mold with dimensions $85 \times 75 \times 1 \mathrm{~mm}$, pressing for $5-7 \mathrm{~min}$ at $230^{\circ} \mathrm{C}$ and a pressure of $5 \mathrm{MPa}$. The control samples of hydrolytic PA6 (HPA6) were produced analogously by compression molding of a medium-viscosity, general purpose commercial grade PA6 (Durethan B30S, Lanxess, USA).

\subsection{Characterization}

Bright field optical measurements of PAMC sizes, roundness and their distributions were performed in an BH-2 microscope (Olympus Corp., Tokyo, Japan) equipped with a DFC200 (Leica Microsystems, Manheim, Germany) digital camera using the Leica Application Suite 4.4 software for image processing. The scanning electron microscopy (SEM) studies were performed in a NanoSEM-200 apparatus of FEI Nova (Hillsboro, USA) using mixed secondary electron/back-scattered electron in-lens detection. The microcapsule samples were observed after sputter-coating with $\mathrm{Au} / \mathrm{Pd}$ alloy in a $208 \mathrm{HR}$ equipment of Cressington Scientific Instruments (Watford, UK) with high-resolution thickness control. The molded samples were observed after cryofracture.

The average viscometric molecular weight $M_{\mathrm{v}}$ of the neat PA6 was determined by intrinsic viscosity measurements in $97 \%$ sulfuric acid at a concentration of $0.2 \mathrm{~g} / \mathrm{dL}$ with a suspended level Ubbelohde viscometer thermostatted at $25^{\circ} \mathrm{C}$. The Mark-Houwink equation for PA6 was used with $K=5.066 \cdot 10^{-4}$ and $\alpha=$ 0.74 [38]. Flow times are recorded as an average of

Table 1. PAMC: sample designation, composition, polymerization yield and granulometry

\begin{tabular}{|c|c|c|c|c|c|}
\hline Sample designation & $\begin{array}{c}\text { Load } \\
{[w t \%]^{a)}}\end{array}$ & $\begin{array}{c}\text { PAMC yield } \\
{[w \%]^{\text {a) }}}\end{array}$ & $\begin{array}{c}\text { Real load, } R L \\
{ }_{[\mathrm{wt} \%]^{\text {b) }}}\end{array}$ & $\begin{array}{l}d_{\max } \\
{[\mu \mathrm{m}]}\end{array}$ & $\begin{array}{c}\text { Roundness, } \\
d_{\max } / d_{\min }\end{array}$ \\
\hline PA6 & - & 56 & - & $25-35$ & 1.2 \\
\hline \multirow{3}{*}{ PA6/CB } & 2 & 60 & - & $25-35$ & $1.2-1.3$ \\
\hline & 6 & 47 & 6.30 & $20-30$ & 1.2 \\
\hline & 10 & 57 & - & $15-30$ & $1.2-1.4$ \\
\hline \multirow{3}{*}{ PA6/CNT } & 2 & 45 & 1.97 & $30-40$ & $1.2-1.3$ \\
\hline & 6 & 52 & 5.33 & $25-35$ & 1.2 \\
\hline & 10 & 54 & 8.00 & $20-35$ & 1.2 \\
\hline \multirow{3}{*}{ PA6/GR } & 2 & 44 & - & $20-30$ & $1.2-1.3$ \\
\hline & 6 & 46 & 6.09 & $20-25$ & 1.2 \\
\hline & 10 & 48 & - & $15-30$ & $1.2-1.3$ \\
\hline \multirow{3}{*}{ PA6/CNF } & 2 & 45 & - & $30-35$ & 1.3 \\
\hline & 6 & 48 & 5.77 & $30-35$ & $1.2-1.3$ \\
\hline & 10 & 54 & - & $20-35$ & $1.2-1.3$ \\
\hline PA6/CNT-GR & $5+5$ & 51 & 8.85 & $25-30$ & $1.2-1.3$ \\
\hline PA6/CNT-CB & $5+5$ & 49 & 9.49 & $15-20$ & 1.3 \\
\hline PA6/GR-CB & $5+5$ & 50 & 8.67 & $25-30$ & $1.2-1.3$ \\
\hline
\end{tabular}

a) As introduced during AAROP, in respect to the starting monomer content;

b) Determined according to Equation (1). 
five runs. The differential scanning calorimetry (DSC) measurements were carried out in a $200 \mathrm{~F} 3$ equipment of Netzsch (Selb, Germany) at a heating rate of $10^{\circ} \mathrm{C} / \mathrm{min}$ under nitrogen purge. The typical sample weights were in the $10-15 \mathrm{mg}$ range. The effective inorganic load in PAMC was established by means of thermogravimetric analysis (TGA) in a Q500 gravimetric balance (TA Instruments, New Castle, USA) heating the samples to $600^{\circ} \mathrm{C}$ at $10^{\circ} \mathrm{C} / \mathrm{min}$ in nitrogen atmosphere. The real load $R L$ of filler in PAMC was calculated according to Equation (1):

$R L=R_{\mathrm{i}}-R_{\mathrm{PA} 6}[\%]$

where $R_{\mathrm{PA} 6}$ is the carbonized residue at $600^{\circ} \mathrm{C}$ of empty PAMC and $R_{\mathrm{i}}$ - that of the respective loaded PAMC measured by TGA.

The tensile tests were performed on an Instron 4505 testing machine (Norwood, USA) at $23 \pm 2^{\circ} \mathrm{C}$ with a standard load cell of $50 \mathrm{kN}$ at a constant crosshead speed of $50 \mathrm{~mm} / \mathrm{min}$. From the different composite plates prepared by compression molding of PAMC, standard specimens were cut out according to DIN 53504-S3. At least five specimens of each sample were studied to calculate the average values and their standard deviation. The engineering stress $\sigma$ was determined as the ratio of the tensile force to the initial cross-section of the sample. The engineering strain $\varepsilon$ was determined as the ratio of the sample gauge length at any time during drawing to that before drawing. The Young modulus $E$ values were obtained from the initial slope of the strainstress curves (until $1 \%$ strain). In all cases conditioned samples stored for ca. 30 days at $23^{\circ} \mathrm{C}$ and $65 \%$ relative humidity were tested. The improvement factor $I F$ for $E$ and $\sigma b r$ values were calculated according to Equation (2):

$I F=\frac{P_{\mathrm{i}}-P_{\mathrm{PA} 6}}{P_{\mathrm{PA} 6}} \cdot 100[\%]$

where $P_{\mathrm{i}}$ is the respective parameter of the composite material and $P_{\mathrm{PA} 6}$ - the same parameter of the neat PA6 matrix.

Synchrotron X-ray diffraction (XRD) measurements were performed in the P03 MINAXS mircofocus beamline at PETRA III, the German Synchrotron Source DESY in Hamburg, Germany. A Pilatus 300 two-dimensional detector (DECTRIS Ltd, Baden, Switzerland) was used, the sample-to-detector distance being $115 \mathrm{~mm}$, and $\lambda=0.969 \AA$. Linear XRD profiles were obtained by radial integration of the 2D XRD images by means of the Fit2D software. Electrical current/voltage measurements were performed in a Keithley 487 pico-ampermeter/voltage source (Keithley Instruments Inc., Cleveland, USA) between -10 and $+10 \mathrm{~V}$ using increasing and/or decreasing modes. To rule out interferences due to external electric field, all measurements were performed in a Faraday cage. The dielectric permittivity $\varepsilon^{\prime}$ was obtained from the geometry of the samples in the shape of a parallel plate capacitor (circular electrodes of $5 \mathrm{~mm}$ diameter and sample average thickness of $600 \mu \mathrm{m}$ ). The measurement of the capacity and the loss factor $\tan \delta$ with a QuadTech (Marlborough, USA) model 1920 precision LCR meter at room temperature and pressure, at frequencies between $100 \mathrm{~Hz}$ and $1 \mathrm{MHz}$. The permittivity $\varepsilon^{\prime}$ of the samples was thus determined according to Equation (3):

$C=\varepsilon^{\prime} \cdot \varepsilon_{0} \cdot \frac{A}{d}$

where $A$ is the area of the capacitor plates and $d-$ the sample thickness.

The electrical d.c. conductivity $\sigma$, the permittivity $\varepsilon^{\prime}$, and the dielectric loss $\varepsilon^{\prime \prime}\left(\tan \delta=\varepsilon^{\prime \prime} / \varepsilon^{\prime}\right)$ were obtained for all composites produced from compression molded PAMC. A standard procedure was followed in which the I-V dependences for all materials were determined and analyzed. From the slope of the graphs (straight lines for Ohmic materials) the resistance $R[\Omega]$ was determined, from which the resistivity $\rho[\Omega \cdot \mathrm{m}]$ and conductivity $\sigma[\mathrm{S} / \mathrm{m}]$ were calculated according to Equation (4):

$\sigma=\frac{1}{\rho}=\frac{1}{R} \cdot \frac{d}{\mathrm{~A}}$

where $A$ is the area and $d$ the thickness of the gold electrodes ( $5 \mathrm{~mm}$ in diameter) deposited by sputtering on both free surfaces of each sample. Four measurements in different parts of each molded samples were performed taking the arithmetical mean as a final value of conductivity.

\section{Results and discussion}

The polymerization of ECL to PAMC is performed in a 1:1 toluene/hydrocarbon mixed solvent boiling in the $120-135^{\circ} \mathrm{C}$ range that is able to dissolve the lactam monomer, the anionic initiator and the activator (Figure 1). The carbon payloads used without 
functionalization are insoluble in the reaction medium. As known from detailed earlier studies [39], the initiation and propagation of lactam AAROP require an anionic initiator and an activator comprising imide links $\mathrm{C}(\mathrm{O})-\mathrm{N}-\mathrm{C}(\mathrm{O})$-. It is important that this catalyst system should remain active in the presence of the carbon payloads and the solvent employed. These requirements determine the selection of the initiator DL and the commercial activator $\mathrm{C} 20$. As indicated in a series of previous studies on AAROP of neat lactams, without any payload, in solution [4042], the growing PA6 chains form initially viscous, low molecular weight particles that upon additional propagation, coalescence and crystallization produce the final empty PAMC. It can be hypothesized that the carbon loads dispersed in the constantly stirred reaction medium will be entrapped into the viscous particles and can possibly nucleate their crystallization thus forming the loaded PAMC. The present study showed that the transformation of the viscous particles into loaded microcapsules without formation of lumps requires an optimized stirring rate (600-800 rpm), maintaining the molar ratio DL/C20 = 2 and keeping the temperature of AAROP below $135^{\circ} \mathrm{C}$.

Table 1 shows the designations of the PAMC samples prepared, the respective polymerization yields and the theoretical carbon filler content. For selected samples the real filler concentration was determined by TGA according to Equation (1). It can be seen that deviations between the real and intended filler content of up to $-2 \%$ are observed only for the higher loads of $10 \mathrm{wt} \%$, while for the rest of the samples the two values are almost identical.

The viscometric average molecular weight $M_{\mathrm{v}}$ of empty PAMC and PAMC loaded with $2 \%$ of CB are 33700 and $37500 \mathrm{~g} / \mathrm{mol}$, respectively. After compression molding of PAMC to plates the $M_{\mathrm{v}}$ values remain unchanged being comparable to the $M_{\mathrm{v}}$ of commercial granulated hydrolytic PA6 with $M_{\mathrm{v}}=$ $37200 \mathrm{~g} / \mathrm{mol}$ and, at the same time, significantly lower than the anionic PA6 $\left(M_{\mathrm{v}}=88500 \mathrm{~g} / \mathrm{mol}\right)$ produced with the same initiator/activator system in the bulk at $165^{\circ} \mathrm{C}[43,44]$. The higher $M_{\mathrm{v}}$ in the latter case is because the bulk AAROP takes place at higher temperature, in the polar molten ECL and in strongly basic medium. These conditions favor complex side reactions leading to partially cross-linked PA6 characterized by increased molecular inhomogeneity [39].

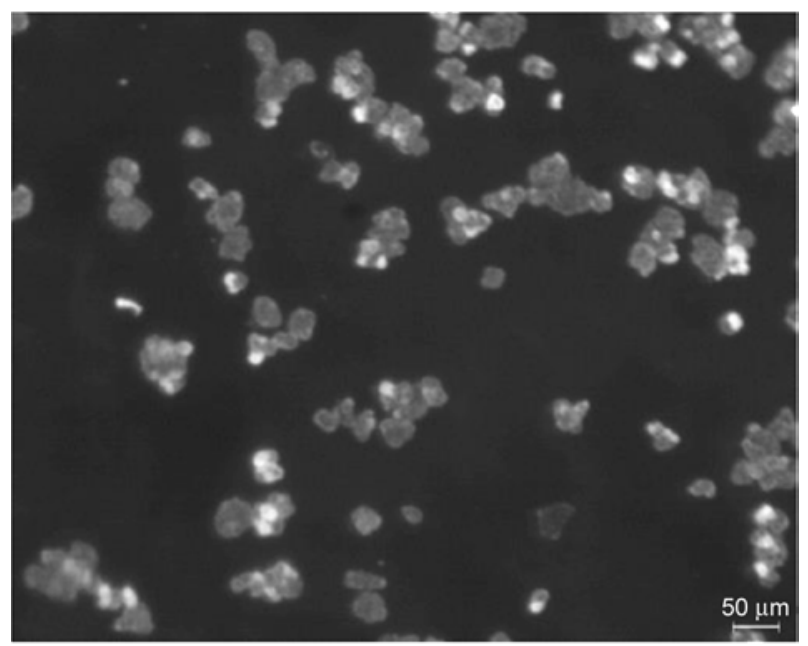

a)
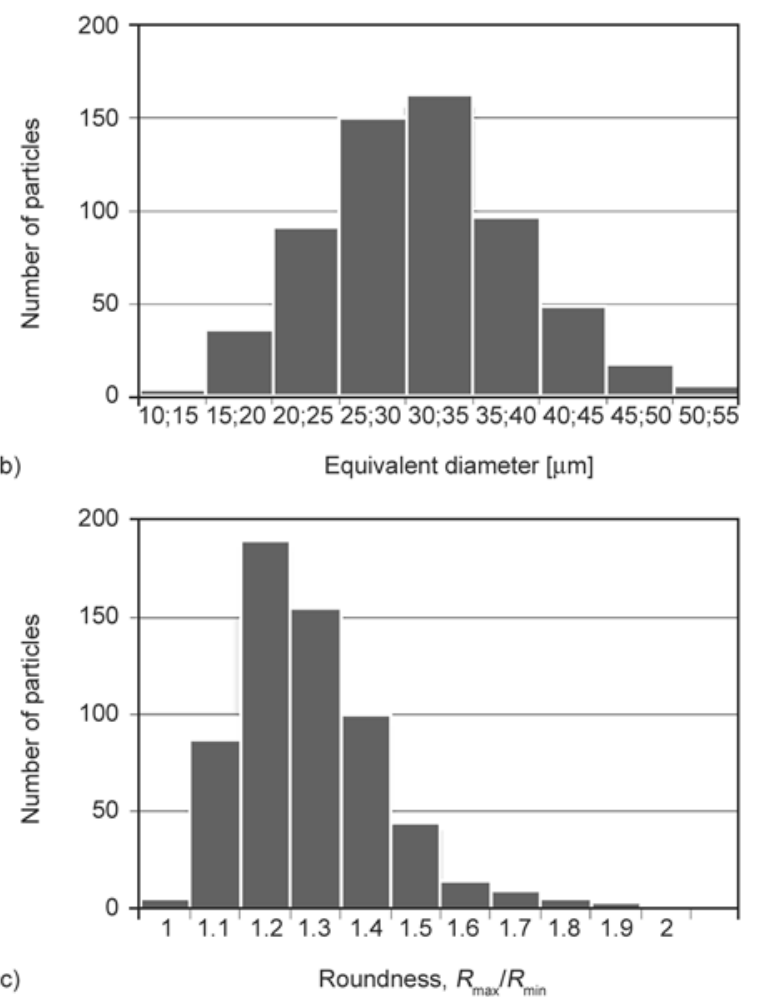

Figure 2. Light microscopy image of PA6/CNT-6\% sample (a), from which the distributions of sizes (b) and shape (c) are determined.

Figure 2 exemplifies the estimation of the granulometry, including the histograms of size distribution of $d_{\max }$ and roundness (i.e., the relation $d_{\max } / d_{\min }$ of the microcapsules) of a selected PAMC sample (PA6/CNT-6\%) by means of light microscopy. Table 1 summarizes these two values for all samples in this study. For the majority of samples obtained at the same AAROP temperature, catalytic system composition and stirring rates, the distributions of both $d_{\max }$ and $d_{\max } / d_{\min }$ are monomodal and close to Gaussian. The most typical PAMC sizes vary 
between $20-35 \mu \mathrm{m}$ with roundness values of $1.2-$ 1.3. Increasing the load broadens slightly both distributions. The type of the C-fillers or their combination reaching an effective load of $9.5 \%$ does not affect significantly the granulometry, which is an indication of good control of the PAMC synthesis. A deeper insight on the morphology of PAMC samples can be obtained by SEM (Figure 3). SEM micrographs show the porosity of the PAMC samples and a scaffold-like morphology, the pores sizes being typically in the $250-500 \mathrm{~nm}$ range. Each microcapsule seems to be formed by the coalescence of several PA6 spheres. This finding is in good agreement with the supposed coalescence-crystallization-precipitation mechanism of AAROP in the presence of the load particles whereby the latter are entrapped into the PAMC-closer to the surface, or deeper in the core. The effect can be observed in Figure $3 \mathrm{c}$ and $3 \mathrm{~d}$ displaying a $\mathrm{CB}$ domain with sizes $1.0 \times 0.5 \mu \mathrm{m}$ on the surface of a microcapsule. Figure $3 e$ and $3 f$ show some GR platelets on the PAMC surface as well as incrusted deeper into the pores. PAMC containing CNT (Figure 3h) display more extended morphology, most probably related to the high aspect ratio of this carbon filler. Having in mind the entrapment of the C-load within PAMC, the term 'microcapsule' was used in this work instead of 'microparticle'.

The morphological changes of loaded PAMC after their compression molding into PA6 hybrid com- posites are shown in Figure 4. As seen from Figure $4 \mathrm{~b}-4 \mathrm{~d}$, even at the high load of $6 \mathrm{wt} \%$, the CNT, $\mathrm{CB}$ and $\mathrm{CNF}$ fillers are finely dispersed within the PA6 matrix, their visible cross-sections being in the nanometer range. Even with the micron-sized GR platelets, a homogeneous distribution is observed (Figure 4e, 4f). These observations confirm the utility of the transformation of loaded PAMC into hybrid composites, proving that this new concept does not need chemical functionalization of the C-filler to avoid agglomeration. Figure $4 \mathrm{~g}$ and $4 \mathrm{~h}$ show the possibility to create homogeneous distribution of two different co-existing carbon fillers: CNT-CB and CNT-GR, respectively.

The results from the DSC measurements with loaded PAMC samples and the respective compression molded plates are presented in Table 2. Figure 5 displays the DSC traces of differently loaded PAMC during the first scan (a), cooling (b) and the second DSC scan (c). All loaded PAMC melt during the first scan at slightly lower temperatures and crystallize at significantly higher temperatures during the cooling after melting, as compared to the neat PA6 microcapsules. For some PAMC samples this difference in the crystallization temperatures can reach 20-23 ${ }^{\circ} \mathrm{C}$ (Table 1, PA6/CB-6, PA6/CNT-CB, Figure $5 \mathrm{~b}$ ) and can be explained with the nucleation effect of the C-filler. The cooling after melting in the presence of CNT and CB fillers) result in double crys-

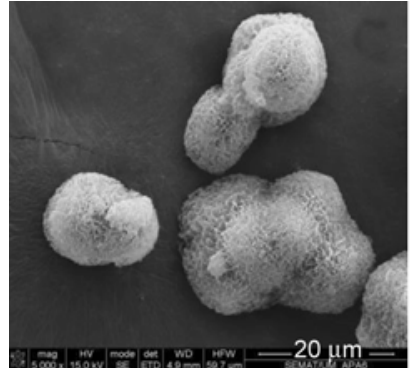

a)

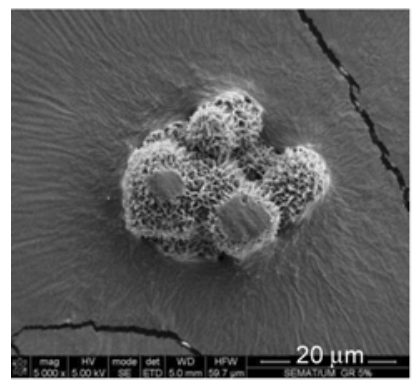

e)

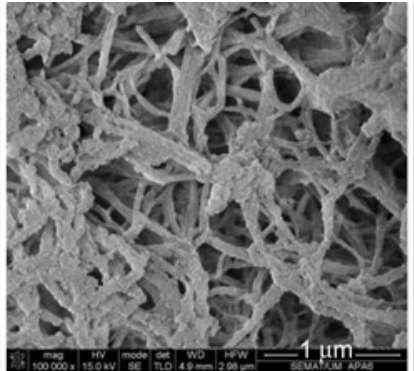

b)

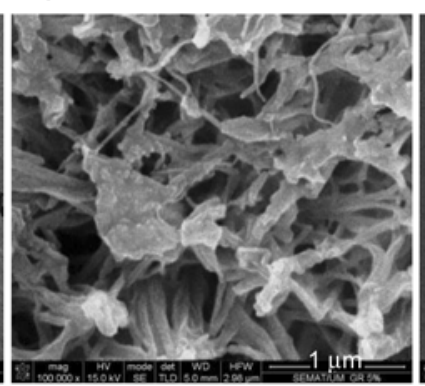

f)

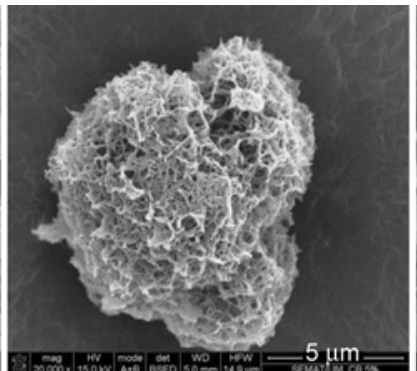

c)

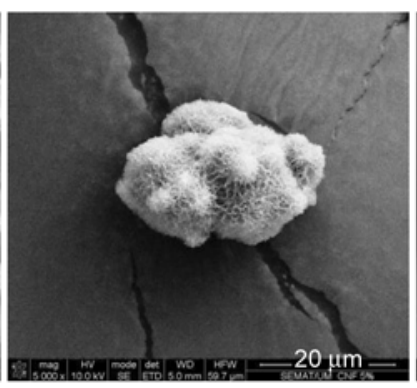

g)

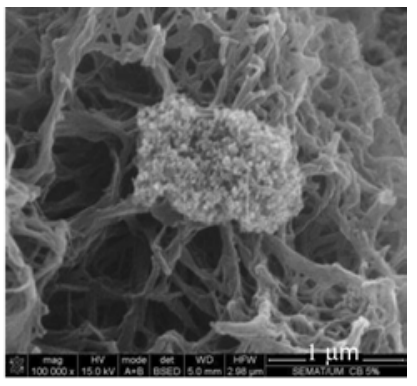

d)

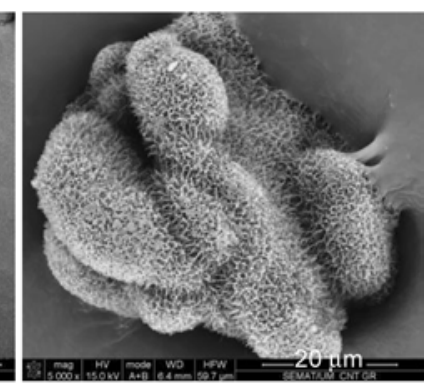

h)

Figure 3. Selected SEM micrographs of PAMC: (a) - PA6; (b) - magnification of (a); (c) - PA6/CB-6\%; (d) - magnification of (c); (e) - PA6/GR-6\%; (f) - magnification of (e); (g) - PA6/CNF-6\%; (h) - PA6/CNT-GR 5+5\%. For sample designation see Table 1 . 


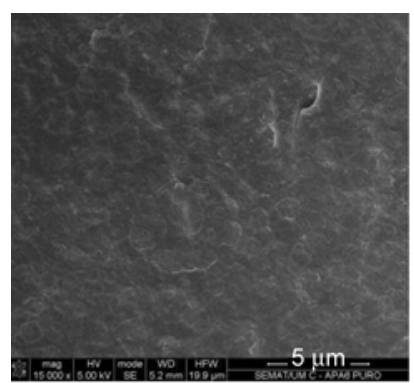

a)

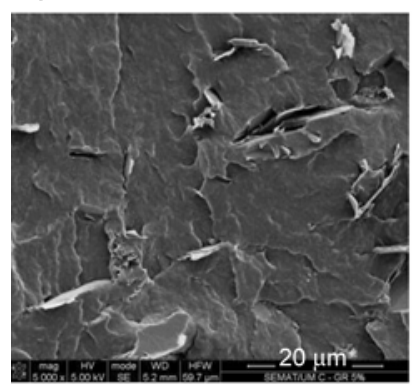

e)

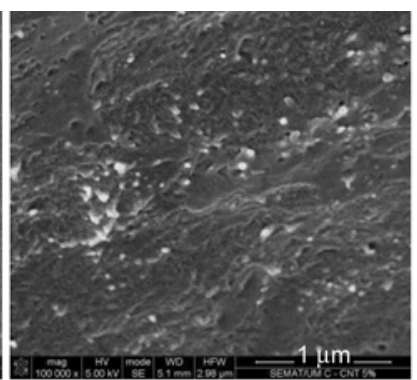

b)

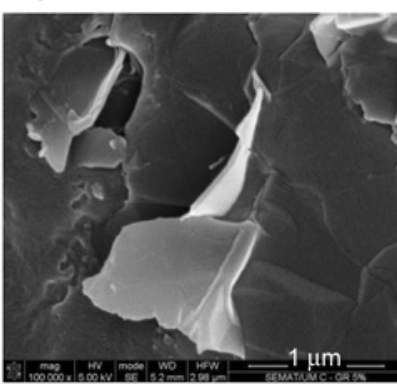

f)

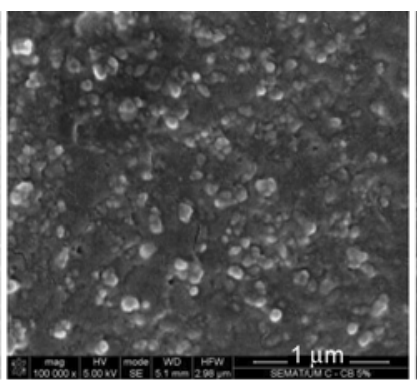

c)

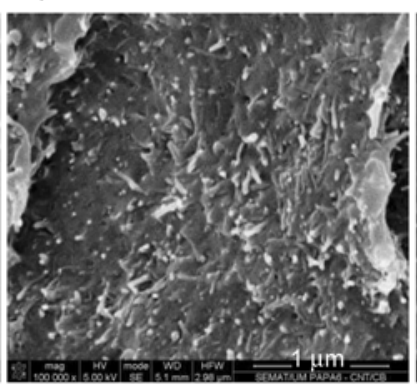

g)

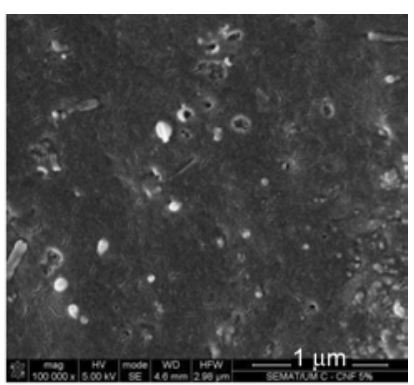

d)

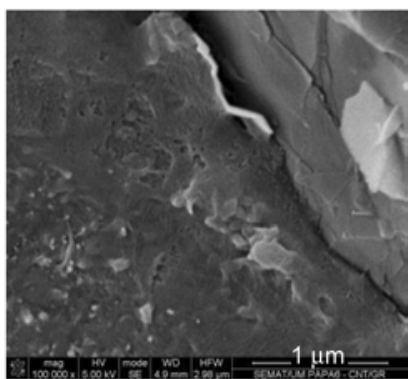

h)

Figure 4. Selected SEM micrographs of compression molded plates obtained from PAMC: (a) - PA6; (b) - PA6/CNT 6\%; (c) - PA6/CB-6\%; (d) - PA6/CNF 6\%; (e) - PA6/GR-6\%; (f) - magnification of (e); (g) - PA6/CNT-CB 5+5\%; (h) - PA6/CNT-GR 5+5\%. For sample designation see Table 1 .

tallization peaks suggesting the coexistence of $\alpha$ and $\gamma$-PA6 polymorphs. During the second DSC scan (Figure $5 \mathrm{c}$ ) the small difference in $T_{\mathrm{m}}$ for neat and carbon-loaded PAMC is preserved, whereby the melting peaks of loaded PAMC (especially those of CNF and GR-containing samples) show a shoulder at lower temperature typical of the $\gamma$-PA6 polymorph [45]. In general, all PAMC samples display $T_{\mathrm{m}}$ values with $15-20^{\circ} \mathrm{C}$ lower than the hydrolytic or bulk anionic PA6 with similar $M_{\mathrm{v}}$ with $T_{\mathrm{m}}=225^{\circ} \mathrm{C}$.
Figure 6 and Table 2 display the thermal behavior of the composite plates prepared by compression molding of PAMC at $230^{\circ} \mathrm{C}$, i.e., well above their $T_{\mathrm{m}}$. As expected, the differences between the $T_{\mathrm{m}}$ values of the samples during the $1^{\text {st }}$ (Figure 6a) and $2^{\text {nd }}$ (Figure 6b) DSC scans are quite negligible, preserving the higher temperatures of dynamic crystallization of the C-loaded composites.

From Table 2 it can also be seen that, as a rule, the crystallinity index $X_{\mathrm{c}}$ of PAMC measured during the

Table 2. DSC data comparison between PAMC and the respective compression molded composites (plate)

\begin{tabular}{|l|l|c|c|c|c|c|}
\hline \multirow{2}{*}{\multicolumn{2}{c|}{ Sample }} & \multicolumn{2}{c|}{$\mathbf{1}^{\text {st }}$ DSC scan } & \multicolumn{2}{c|}{$\mathbf{2}^{\text {nd }}$ DSC scan } & Recrystallization $^{*}$ \\
\cline { 3 - 7 } & & $\begin{array}{c}\boldsymbol{T}_{\mathbf{m}} \\
{\left[{ }^{\circ} \mathbf{C}\right]}\end{array}$ & $\begin{array}{c}\boldsymbol{X} \\
{[\%]}\end{array}$ & $\begin{array}{c}\boldsymbol{T}_{\mathbf{g}} \\
{\left[{ }^{\circ} \mathbf{C}\right]}\end{array}$ & $\begin{array}{c}\boldsymbol{X} \\
{[\%]}\end{array}$ & $\begin{array}{c}\boldsymbol{T}_{\mathbf{c}} \\
{\left[{ }^{\circ} \mathbf{C}\right]}\end{array}$ \\
\hline \multirow{2}{*}{ PA6 } & PAMC & 211.3 & 35.0 & 34.4 & 20.6 & 151.1 \\
\cline { 2 - 7 } & plate & 212.8 & 24.2 & 46.8 & 21.8 & 159.8 \\
\hline \multirow{2}{*}{ PA6/CB-6 } & PAMC & 201.2 & 28.9 & 37.4 & 24.6 & 174.3 \\
\cline { 2 - 7 } & plate & 206.9 & 27.6 & 46.9 & 27.6 & 173.3 \\
\hline \multirow{2}{*}{ PA6/CNT-6 } & PAMC & 207.0 & 39.4 & 33.2 & 23.0 & 169.7 \\
\cline { 2 - 7 } & plate & 209.3 & 26.5 & 45.8 & 26.5 & 168.8 \\
\hline \multirow{2}{*}{ PA6/GR-6 } & PAMC & 206.1 & 37.9 & 42.9 & 22.8 & 165.8 \\
\cline { 2 - 7 } & plate & 206.6 & 28.8 & 45.5 & 26.8 & 167.4 \\
\hline \multirow{2}{*}{ PA6/CNF-6 } & PAMC & 206.2 & 38.1 & 39.2 & 22.5 & 163.3 \\
\cline { 2 - 7 } & plate & 208.6 & 29.1 & 45.8 & 26.8 & 169.0 \\
\hline \multirow{2}{*}{ PA6/CNT-CB 5 +5 } & PAMC & 198.0 & 32.4 & 51.4 & 27.6 & 171.4 \\
\cline { 2 - 7 } & plate & 203.1 & 23.4 & 55.6 & 28.6 & 173.3 \\
\hline \multirow{2}{*}{ PA6/GR-CB 5+5 } & PAMC & 206.9 & 30.9 & 41.5 & 21.7 & 171.4 \\
\cline { 2 - 7 } & plate & 200.9 & 30.6 & 42.3 & 25.9 & 173.0 \\
\hline
\end{tabular}

${ }^{*}$ Determined after $1^{\text {st }}$ DSC scan under fast cooling down. 

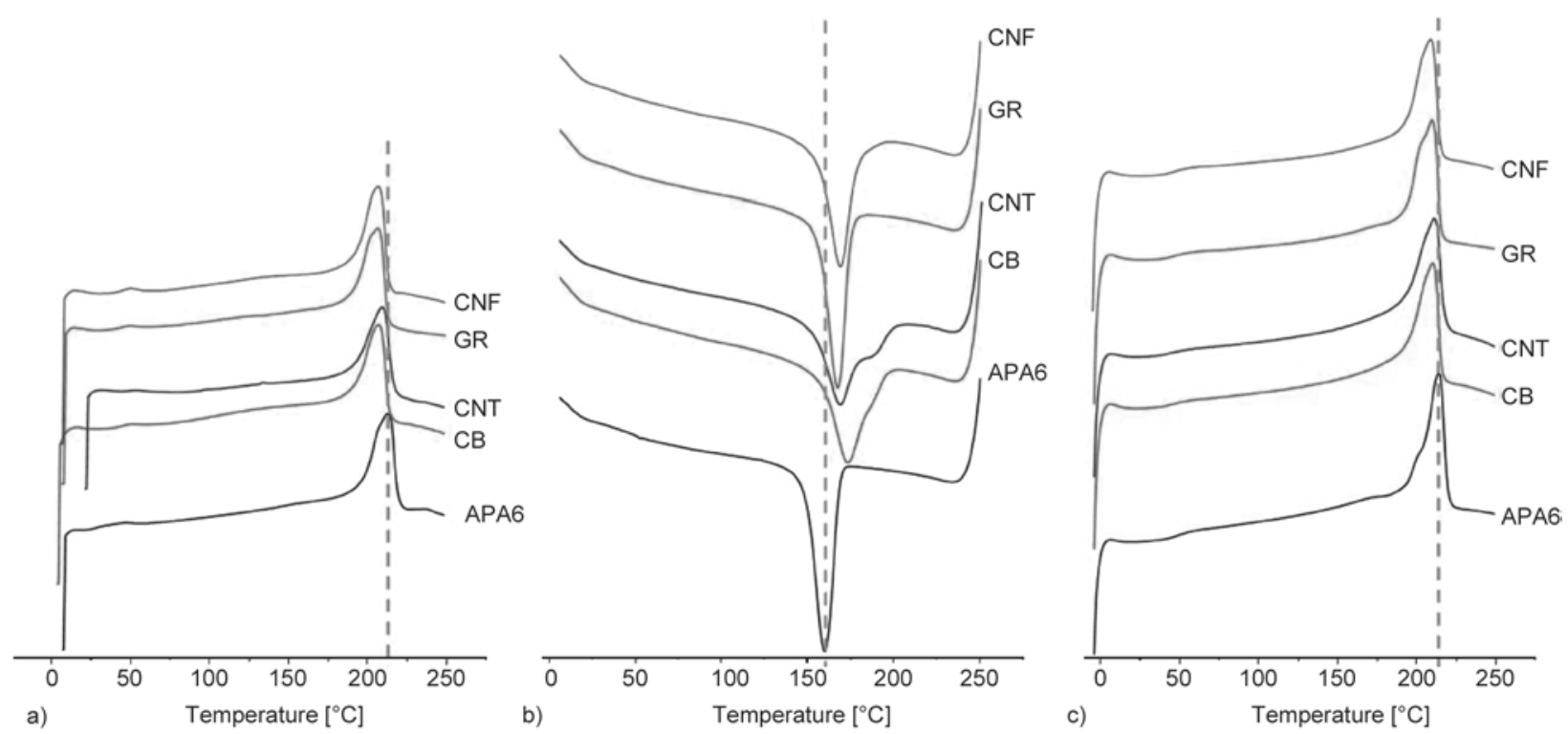

Figure 5. DSC traces of loaded PAMC containing $6 \%$ of the indicated allotrope: (a) - first DSC scan; (b) - cooling down to $30^{\circ} \mathrm{C}$ after $1^{\text {st }} \mathrm{scan}$; (c) $-2^{\text {nd }} \mathrm{DSC}$ scan
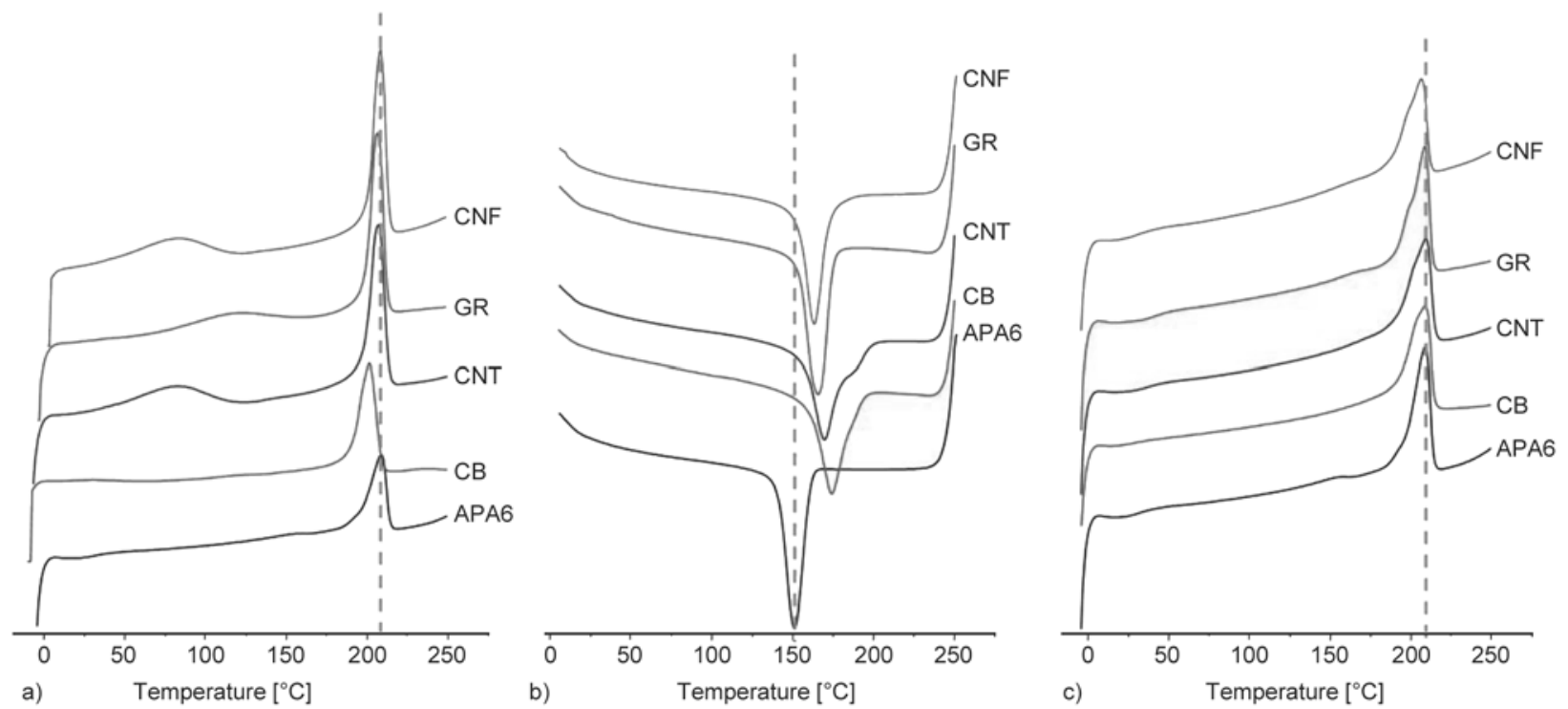

Figure 6. DSC traces of compression molded composite plates containing $6 \%$ of the indicated allotrope: (a) - first DSC scan; (b) - fast cooling down to $30^{\circ} \mathrm{C}$ after $1^{\text {st }}$ scan; (c) - $2^{\text {nd }}$ DSC scan

$1^{\text {st }} \mathrm{scan}$ is higher than that of the respective compression molded composite. The difference depends on the $\mathrm{C}$-filler and can reach $12-15^{\circ} \mathrm{C} \%$ as in PA6/GR$\mathrm{CB}$ and PA6/CNT-6 compositions, as well as for the neat PAMC/PA6 plate pair. This difference equalizes after the $2^{\text {nd }}$ scan in the range of $3-4^{\circ} \%$ for all samples. This observation confirms the previously established fact that the thermal history of the PA6 sample is of prime importance for the crystallinity index $[45,46]$. During AAROP, the PAMC samples were synthesized and crystallized at isothermal conditions $\left(\sim 135^{\circ} \mathrm{C}\right.$ for one hour $)$ and then cooled gradually to room temperature i.e., no melting occurred. The molded plates were obtained after melt- ing at $230{ }^{\circ} \mathrm{C}$ and cooling down with ca. $20^{\circ} \mathrm{C} / \mathrm{min}$ to room temperature. That is why the second DSC scan of PAMC and the first scan of plates show similar crystallinities. Another comparison based on the data in Table 2 can be made between the glass-transition temperatures $T_{\mathrm{g}}$ of loaded PAMC and their molded composites. The microcapsules show lower $T_{\mathrm{g}}$ values related to a higher segmental mobility, this difference being best expressed in the empty PAMC/neat PA6 pair and in that with composition PA6/CNT-6. The purpose of the TGA studies of PAMC shown in Figure 7 is to establish the thermal stability of the samples as a function of: (i) carbon load type, (ii) its amount and (iii) the presence of two-component 
filler system. The determination of the real C-filler content in the basis of the carbonized residue at $600^{\circ} \mathrm{C}$ was discussed previously. Figure 7 shows that all hybrid PAMC display improved thermal stability. In the empty PAMC the thermal degradation starts at $T_{\mathrm{S}}=295^{\circ} \mathrm{C}$ and the maximum degradation rate is reached at $T_{\mathrm{MDR}}=339^{\circ} \mathrm{C}$, whereas with the best performing PA6/GR-6 microcapsules these val-
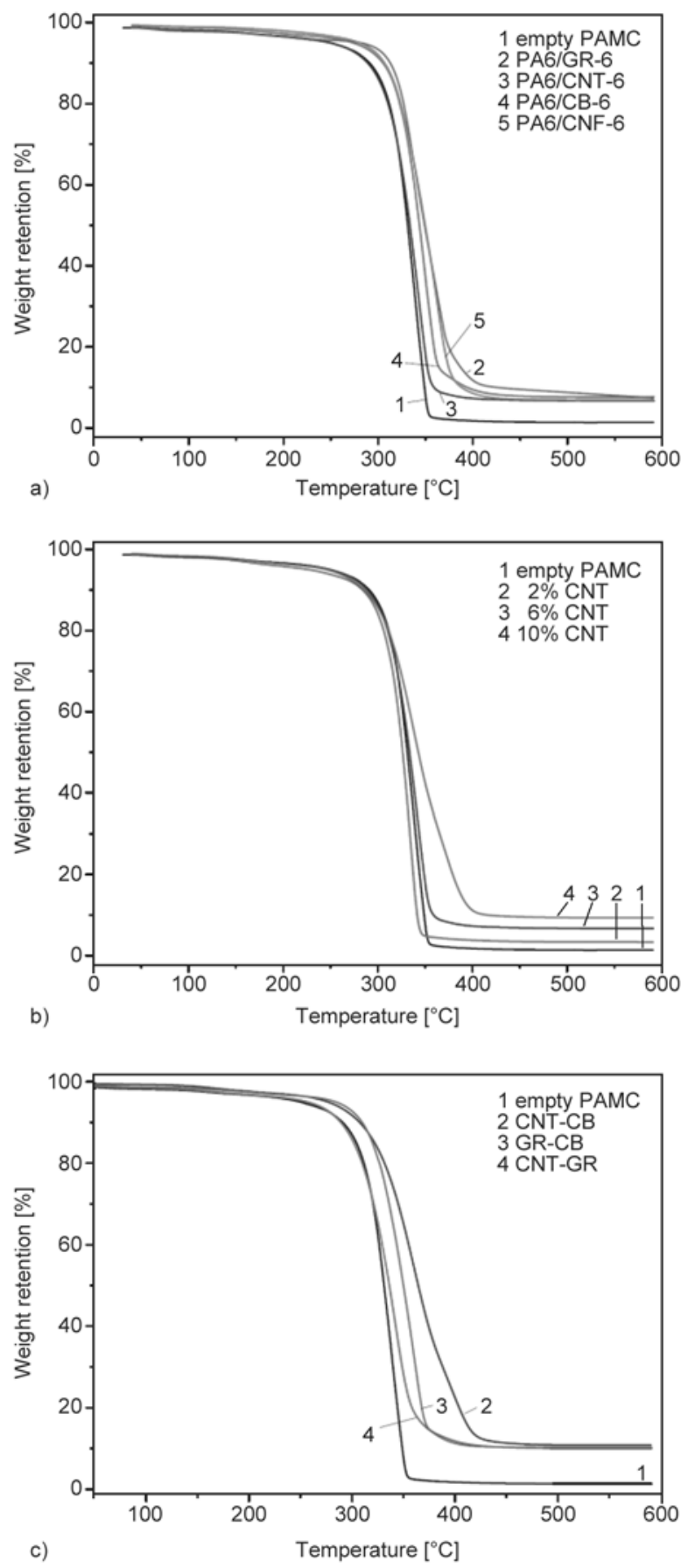

Figure 7. TGA traces of PAMC samples (in $\mathrm{N}_{2}$ atmosphere at $10^{\circ} \cdot \mathrm{min}^{-1}$ heating rate): (a) - as a function of the C-filler type, (b) - as a function of the percentage of CNT, (c) - PAMC with mixed fillers, $5+5 \%$ ues are 316 and $364^{\circ} \mathrm{C}$, respectively. The respective temperatures of the CNT, CNF and CB-loaded PAMC are within ca. $20^{\circ} \mathrm{C}$ difference. Increasing the amount of CNT from 2 to $10 \%$ (Figure $7 \mathrm{~b}$ ) did not change either $T_{\mathrm{S}}$ or $T_{\mathrm{MDR}}$ however a second degradation process was registered with $T_{\mathrm{MDR}}=370^{\circ} \mathrm{C}$. The PAMC with two fillers (Figure 7c) displayed better thermostability because of the higher filler content. Notably, PAMC containing the CNT-CB mixture displayed $T_{\mathrm{S}}$ and $T_{\mathrm{MDR}}$ values of 310 and $400^{\circ} \mathrm{C}$ i.e., $60-65^{\circ} \mathrm{C}$ higher than the empty PAMC. This synergism in PAMC with mixed fillers can be interesting in tailoring the thermal stability of PA6/C-allotrope composite materials. The TGA traces of PAMC in Figure 7 do not show significant weight losses at low temperatures typical for the presence of ECL monomer or oligomer products. Together with the average $M_{\mathrm{v}}$ values in Table 1 , this is an indication that all PAMC are practically made of high molecular weight PA6.

The crystalline structure of PAMC and the molded plates was additionally studied by XRD (Figure 8, Table 3). As seen from Figure 8a, neat CNT, GR and $\mathrm{CNF}$ are crystalline materials that contain clear diffraction peaks, while $\mathrm{CB}$ was unable to produce coherent scattering at wide angles and therefore should be considered amorphous. The two reflections at $2 \theta=16-17$ and $27-28^{\circ}$ in CNT correspond to the (002) and (100) crystalline planes. In these same two ranges GR displays multiple and narrower reflections for the (002), (101) and (102)/(003) crystalline planes, which is a proof of more perfect crystallites. With the CNF fillers the (002) and (101) peaks are shifted at slightly lower $2 \theta$ positions and are accompanied by diffuse scattering which is an indication of lower and imperfect crystallinity.

The diffraction curves of PAMC with the same amount of C-fillers are presented in Figure $8 \mathrm{~b}$ and show a clear predominance the monoclinic $\alpha$-PA6 polymorph with its two characteristic reflections at $2 \theta=13.2$ and $15.6^{\circ}$. They correspond to the $\alpha 200$ and $\alpha 002 / 202$ crystal planes formed between adjacent chains by van der Waals forces and H-bonds, respectively. Judging from the slightly lower intensity of the former peak, it seems that in all PAMC the crystal growth along the direction of the van der Waals forces is impeded. The patterns of the compression molded plates with the same composition (Figure 8c) also display the presence of $\alpha$-polymorph however the appearance of a weak shoulder at $9-10^{\circ}$ 

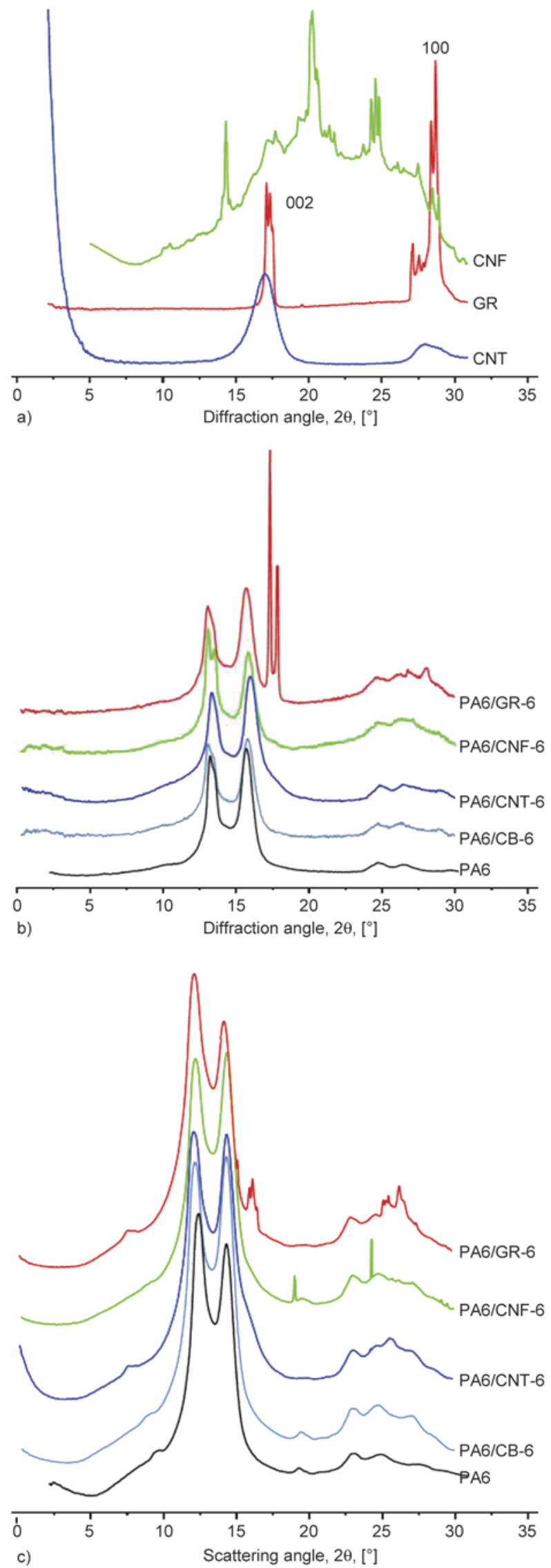

Figure 8. Linear WAXS profiles of: (a) - crystalline pure C-allotropes; (b) - PAMC; (c) - molded plates corresponding to the $\gamma 020$ reflection verifies a larger amount of $\gamma$-PA6. Analyzing the intensity of the two $\alpha$-reflections, it seems that only in the GR-containing composite the crystal growth has a preferred direction, which is the H-bond direction. In the CNT, $\mathrm{CB}$ and $\mathrm{CNF}$ composites it seems that compression molding equalizes the crystal growth in both directions.

Table 3 summarizes the polymorph content, the crystallinity index and the d-spacings of the $\alpha$ - and $\gamma$-PA6 polymorphs in the as-prepared PAMC and the respective compression molded plates. These data were obtained by peak-fitting the linear diffraction profiles as previously indicated [47]. Judging by the $\alpha / \gamma$ ratio, it can be concluded that the asprepared PAMC are up to 3-4 times richer in $\alpha$-PA6 as compared to the molded plates with the same composition, the largest difference being found in the GR-containing samples. The polymorph ratio becomes closer to unity after melt processing which was established in earlier studies on PA6 obtained by bulk AAROP [44]. The analysis of the d-spacings shows that within the PAMC or molded plates datasets the $\mathrm{C}$-filler does not change the unit cell dimension, whereas the transitions from PAMC to molded plates results in an observable increase of these parameters.

Table 4 displays the mechanical properties in tension of the composites produced from PAMC loaded with different amounts and types of carbon fillers. All composites display higher Young's modulus values. The improvement factor $I F$ calculated according to Equation (2) is always positive and increases with $25-40 \%$ for samples with $10 \%$ carbon loads - individual or mixed. The stress at break $\sigma_{\mathrm{br}}$ values seems to depend much stronger on the $\mathrm{C}$-filler type. Thus, the samples with 6 and $10 \mathrm{wt} \% \mathrm{CB}$ as well as the systems with CNT-CB and GR-CB modification showed lower tensile strength as compared to the matrix PA6. The rest of the carbon fillers and notably the multi-walled CNT increased the strength with up to $27 \%$. As expected, the elongation at break $\varepsilon_{b r}$ as a rule drops abruptly even with the lowest filler content passing from ductile (neat PA6) to brittle failure. The only exception is the composite with $2 \%$ of GR. From all C-fillers only CB affects negatively (alone or in combination with other C-fillers) the composite's tensile strength (Table 4). This might be related to the particulate morphology of 
Table 3. Polymorph content, WAXS crystallinity and long spacing data extracted from the WAXS profiles in Figure 8

\begin{tabular}{|c|c|c|c|c|c|c|c|c|c|c|}
\hline \multicolumn{2}{|c|}{ Sample } & $\begin{array}{c}\alpha \\
{[\%]}\end{array}$ & $\begin{array}{c}\gamma \\
{[\%]}\end{array}$ & $\begin{array}{c}X_{\mathbf{c}} \\
{[\%]}\end{array}$ & $\alpha / \gamma$ & $\begin{array}{c}d_{\alpha(200)} \\
{[\AA \tilde{A}]}\end{array}$ & $\begin{array}{c}d_{a(002) /(202)} \\
{[\AA]}\end{array}$ & $\begin{array}{l}d_{\gamma(\mathbf{0 2 0})} \\
{[\tilde{\AA}]}\end{array}$ & $\begin{array}{c}d_{\gamma(001)} \\
[\AA]]\end{array}$ & $\begin{array}{c}d_{\gamma(\mathbf{2 0 0})} \\
{[\AA \AA]}\end{array}$ \\
\hline \multirow{2}{*}{ PA6 } & PAMC & 39.4 & 11.7 & 51.1 & 3.37 & 4.14 & 3.56 & - & 4.12 & 3.81 \\
\hline & \begin{tabular}{|l|} 
plate \\
\end{tabular} & 25.9 & 18.5 & 44.4 & 1.40 & 4.48 & 3.89 & 5.86 & 4.46 & 4.21 \\
\hline \multirow{2}{*}{ PA6/CB-6 } & PAMC & 34.9 & 8.7 & 43.6 & 4.00 & 4.19 & 3.57 & - & 4.13 & 3.68 \\
\hline & plate & 24.8 & 23.3 & 48.1 & 1.06 & 4.52 & 3.91 & 5.72 & 4.50 & 4.07 \\
\hline \multirow{2}{*}{ PA6/CNT-6 } & PAMC & 27.4 & 9.2 & $46.5^{*}$ & 2.98 & 4.17 & 3.56 & - & 4.11 & 3.89 \\
\hline & plate & 25.5 & 20.5 & $52.1^{*}$ & 1.24 & 4.50 & 3.89 & 6.42 & 4.44 & 4.17 \\
\hline \multirow{2}{*}{ PA6/GR-6 } & PAMC & 32.2 & 5.4 & $59.3^{*}$ & 6.15 & 4.21 & 3.59 & - & 4.06 & 3.86 \\
\hline & plate & 29.6 & 21.4 & $53.2^{*}$ & 1.38 & 4.58 & 3.91 & 6.43 & 4.47 & 4.23 \\
\hline
\end{tabular}

${ }^{*}$ For the samples containing GR and CNT, $X_{\mathrm{c}}>\alpha+\gamma$, the difference accounting for the crystalline peaks of the fillers.

Table 4. Mechanical properties of composite plates compression molded from loaded PAMC

\begin{tabular}{|c|c|c|c|c|c|c|}
\hline $\begin{array}{c}\text { Sample } \\
\text { designation }\end{array}$ & $\begin{array}{l}\text { Load } \\
{[w t \%]}\end{array}$ & $\begin{array}{c}\text { Young's modulus, } E \\
\text { [GPA] }\end{array}$ & $\begin{array}{l}\boldsymbol{I F}^{*} \\
{[\%]}\end{array}$ & $\begin{array}{c}\text { Tensile strength, } \sigma_{\mathrm{br}} \\
{[\mathrm{MPa}]}\end{array}$ & $\begin{array}{l}I F^{*} \\
{[\%]}\end{array}$ & $\begin{array}{c}\text { Deformation at break, } \varepsilon_{\mathrm{br}} \\
{[\%]}\end{array}$ \\
\hline PA6 & - & $1.72 \pm 0.09$ & - & $71.8 \pm 4.3$ & - & $19.2 \pm 1.5$ \\
\hline \multirow{3}{*}{ PA6/CB } & 2 & $2.03 \pm 0.15$ & 18.0 & $73.1 \pm 3.5$ & 1.81 & $4.3 \pm 0.2$ \\
\hline & 6 & $2.27 \pm 0.03$ & 32.0 & $53.3 \pm 3.9$ & -25.8 & $2.6 \pm 0.3$ \\
\hline & 10 & $2.37 \pm 0.13$ & 37.8 & $60.0 \pm 4.5$ & -16.4 & $3.6 \pm 0.6$ \\
\hline \multirow{3}{*}{ PA6/CNT } & 2 & $2.09 \pm 0.02$ & 21.5 & $81.3 \pm 1.6$ & 13.2 & $9.3 \pm 1.8$ \\
\hline & 6 & $2.24 \pm 0.11$ & 30.2 & $91.3 \pm 1.3$ & 27.1 & $7.3 \pm 1.5$ \\
\hline & 10 & $2.31 \pm 0.10$ & 34.3 & $87.2 \pm 4.9$ & 21.5 & $6.2 \pm 1.3$ \\
\hline \multirow{3}{*}{ PA6/GR } & 2 & $2.01 \pm 0.04$ & 16.9 & $80.1 \pm 1.3$ & 11.6 & $19.4 \pm 2.9$ \\
\hline & 6 & $2.30 \pm 0.02$ & 33.7 & $84.7 \pm 1.7$ & 18.0 & $8.6 \pm 0.6$ \\
\hline & 10 & $2.43 \pm 0.08$ & 41.3 & $76.9 \pm 2.6$ & 7.1 & $6.8 \pm 1.3$ \\
\hline \multirow{3}{*}{ PA6/CNF } & 2 & $2.13 \pm 0.04$ & 23.8 & $74.0 \pm 1.5$ & 3.1 & $5.6 \pm 2.0$ \\
\hline & 6 & $2.11 \pm 0.11$ & 22.7 & $77.3 \pm 4.3$ & 7.7 & $4.9 \pm 0.6$ \\
\hline & 10 & $2.14 \pm 0.06$ & 24.4 & $74.4 \pm 4.3$ & 3.6 & $4.3 \pm 0.4$ \\
\hline PA6/CNT-GR & $5+5$ & $2.33 \pm 0.05$ & 35.5 & $84.9 \pm 2.1$ & 18.3 & $6.3 \pm 0.2$ \\
\hline PA6/CNT-CB & $5+5$ & $2.38 \pm 0.11$ & 38.4 & $67.3 \pm 3.4$ & -6.3 & $3.4 \pm 0.3$ \\
\hline PA6/GR-CB & $5+5$ & $2.36 \pm 0.13$ & 37.2 & $59.1 \pm 3.9$ & -17.7 & $2.9 \pm 0.2$ \\
\hline
\end{tabular}

${ }^{*}$ Determined according to Equation (2).

All data are for samples conditioned for more than 10 days at room temperature and $65 \%$ relative humidity.

CB and its amorphous structure, whereas CNT, GR and CNF are crystalline materials organized as platelets or fibers with significant aspect ratio.

The d.c. electrical conductivity $\sigma$, the permittivity $\varepsilon^{\prime}$, the dielectric loss $\varepsilon^{\prime \prime}$ and the loss factor $\tan \delta=\varepsilon^{\prime \prime} / \varepsilon^{\prime}$ were determined for all composites produced from compression molded PAMC (Figure 9, Table 5) using Equation (3) and (4). As expected, neat PA6 is insulator with $\sigma$ values of above $10^{-10} \mathrm{~S} / \mathrm{m}$. The well-dispersed according to SEM data $\mathrm{CB}$ and $\mathrm{CNT}$ nanofillers with effective loads of $6-10 \mathrm{wt} \%$ result in a notable growth of $\sigma$ with $8-9$ decades reaching values characteristic of semiconductors. Mixtures of carbon allotrope fillers such GR/CNT and especially $\mathrm{CB} / \mathrm{CNT} 5+5 \mathrm{wt} \%$ also result in $\sigma$ values of ca. $10^{-1} \mathrm{~S} / \mathrm{m}$, which is an indication that a part of the expensive CNTs can be substituted by the much cheaper GR or CB maintaining the good conductivity values. Similar synergism related to conductivity
Table 5. Electrical properties of PA6 hybrid composites obtained by compression molding of loaded PAMC. For more details see the text.

\begin{tabular}{|c|c|c|c|c|}
\hline $\begin{array}{c}\text { Sample } \\
\text { designation }\end{array}$ & $\begin{array}{c}\text { Load } \\
{[\%]}\end{array}$ & $\begin{array}{c}\text { Conductivity, } \\
\sigma \\
{\left[\mathbf{S} \cdot \mathbf{m}^{-1}\right]}\end{array}$ & $\begin{array}{c}\text { Permitivity, } \\
\varepsilon^{\prime}\end{array}$ & $\begin{array}{l}\text { Loss factor, } \\
\quad \tan \delta\end{array}$ \\
\hline PA6 & - & $6.21 \cdot 10^{-10}$ & $6.50 \cdot 10^{0}$ & $5.31 \cdot 10^{-2}$ \\
\hline \multirow{3}{*}{$\mathrm{PA} 6 / \mathrm{CB}$} & 2 & $4.57 \cdot 10^{-9}$ & $1.11 \cdot 10^{1}$ & $8.39 \cdot 10^{-2}$ \\
\hline & 6 & $1.99 \cdot 10^{-5}$ & $5.38 \cdot 10^{1}$ & $4.19 \cdot 10^{-1}$ \\
\hline & 10 & $2.02 \cdot 10^{-2}$ & $5.32 \cdot 10^{2}$ & $1.97 \cdot 10^{0}$ \\
\hline \multirow{3}{*}{ PA6/CNT } & 2 & $6.58 \cdot 10^{-5}$ & $1.53 \cdot 10^{1}$ & $1.64 \cdot 10^{-1}$ \\
\hline & 6 & $1.17 \cdot 10^{-2}$ & $3.48 \cdot 10^{1}$ & $2.90 \cdot 10^{-2}$ \\
\hline & 10 & $1.26 \cdot 10^{-1}$ & $3.93 \cdot 10^{2}$ & $1.19 \cdot 10^{2}$ \\
\hline \multirow{3}{*}{ PA6/GR } & 2 & $5.97 \cdot 10^{-9}$ & $7.27 \cdot 10^{-2}$ & $6.99 \cdot 10^{-2}$ \\
\hline & 6 & $3.42 \cdot 10^{-9}$ & $9.60 \cdot 10^{0}$ & $1.01 \cdot 10^{-1}$ \\
\hline & 10 & $3.51 \cdot 10^{-9}$ & $1.23 \cdot 10^{1}$ & $1.13 \cdot 10^{-1}$ \\
\hline \multirow{3}{*}{$\mathrm{PA} 6 / \mathrm{CNF}$} & 2 & $3.07 \cdot 10^{-9}$ & $8.77 \cdot 10^{0}$ & $9.51 \cdot 10^{-2}$ \\
\hline & 6 & $6.55 \cdot 10^{-6}$ & $2.90 \cdot 10^{1}$ & $3.72 \cdot 10^{-1}$ \\
\hline & 10 & $1.13 \cdot 10^{-6}$ & $3.95 \cdot 10^{1}$ & $3.23 \cdot 10^{-1}$ \\
\hline $\mathrm{CNT} / \mathrm{GR}$ & \multirow{3}{*}{$5+5$} & $2.22 \cdot 10^{-2}$ & $4.80 \cdot 10^{1}$ & $1.89 \cdot 10^{1}$ \\
\hline $\mathrm{CNT} / \mathrm{CB}$ & & $1.16 \cdot 10^{-1}$ & $1.42 \cdot 10^{3}$ & $5.53 \cdot 10^{0}$ \\
\hline $\mathrm{GR} / \mathrm{CB}$ & & $3.12 \cdot 10^{-9}$ & $3.10 \cdot 10^{1}$ & $2.20 \cdot 10^{-1}$ \\
\hline
\end{tabular}


was reported recently by Socher et al. for of CNT and CB fillers in PA12 matrices [3]. The CNF filler alone produced only a slight increase of $\sigma$ (3 decades
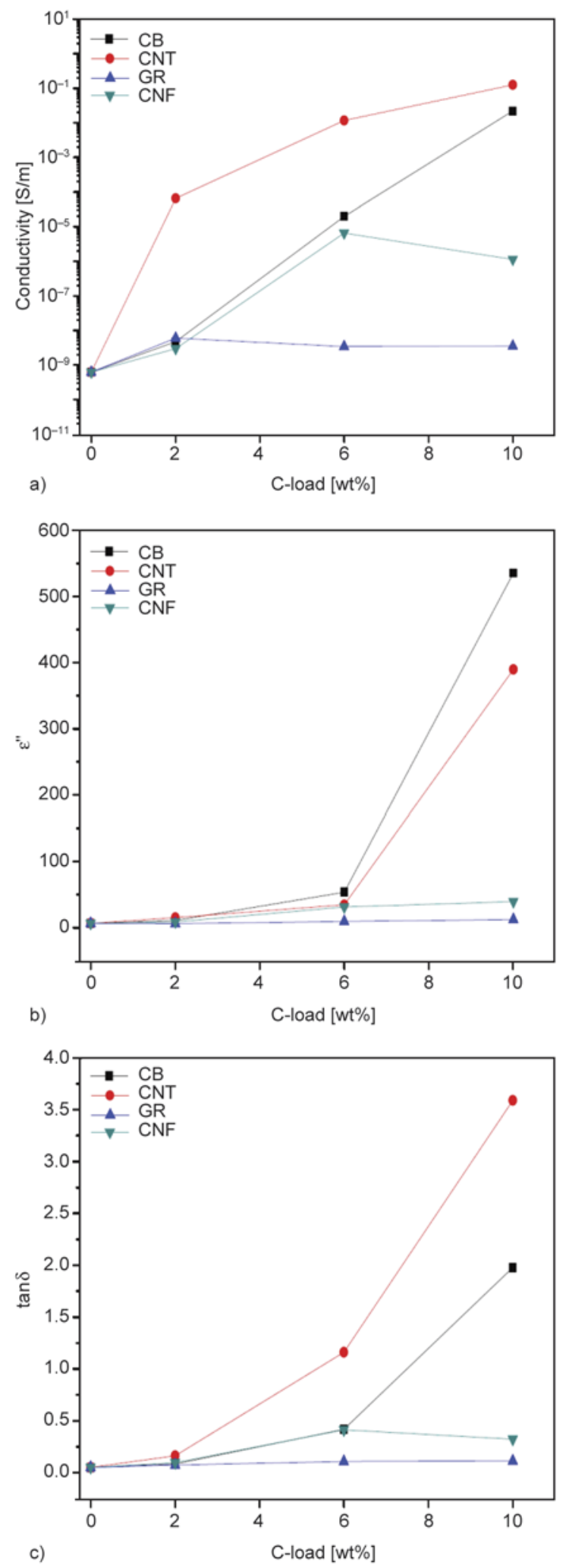

Figure 9. Electrical properties of molded PA6/C-filler composites as a function of composition: (a) - conductivity, $\sigma[\mathrm{S} / \mathrm{m}]$; (b) - permittivity, $\varepsilon^{\prime}$; (c) - loss factor $\tan \delta$ at $10 \mathrm{wt} \%$ load), while GR conveyed no additional conductivity to the matrix material even at the highest loads (Table 5). As seen from Figure 9a, the slope of the semi-logarithmic curves $\log _{10}(\sigma)=f[\mathrm{C}$ content] depends on the type of the filler being the steepest with CNT. Relating these results to the observation of morphology of CNT, CB and CNF hybrids in Figure 4, it can be inferred that the nanometric size of the load particles and their homogeneous distribution within the PA6 matrix are important factors enhancing the electrical conductivity. Apparently, the aspect ratio of the carbon particles being the highest in the CNT seems also to contribute to the increase. As regards the $\varepsilon^{\prime}$ and $\tan \delta$ values (Figures 9b and 9c, Table 5) they can be controlled by changing appropriately the C-filler type and concentration. Thus, PA6/CB-10 wt $\%$ and PA6/CNT-CB samples possess high conductivity and high permittivity combined with relatively low loss factor, while in the PA6/CNT-10 wt $\%$ sample the loss factor is 100 times larger at a similar conductivity and permittivity values, allowing in this way to tailor composite electrical properties for specific applications.

\section{Conclusions}

A one-step in-situ process was used to synthesize porous PAMC loaded with four different $\mathrm{C}$-fillers based on suspension AAROP of ECL in a 1:1 toluene/ xylene mixed solvent. The PAMC formation most probably passes through entrapping of the load particles into initially formed viscous aggregates of growing macromolecules followed by coalescence and crystallization. This novel method is characterized by short polymerization times of ca. $60 \mathrm{~min}$, low polymerization temperatures $\left(\sim 135^{\circ} \mathrm{C}\right)$ and high, reproducible conversion to high molecular weight PAMC. It can introduce high loads of one or more powdered C-fillers into PAMC, and is suitable for scale-up to industrial production. Transforming these loaded PAMC into composites by conventional compression molding produces good homogenization of the conductive filler without the need of its functionalization. This results in improved mechanical properties of the hybrid composite even at high filler loads. There are all indications that preparing PAMC with mixed C-loads could be a way to manipulate the whole set of electric and dielectric properties of the molded composites adjusting them to different target applications. 


\section{Acknowledgements}

The authors gratefully acknowledge the financial support of the Portuguese Foundation for Science and Technology (FCT) by the Strategic Project LA25/2013-2014, the post-doctoral grant SFRH/BPD/45252/2008 and the grant by the MiNaXS beamline of DESY - Hamburg, Germany. This work was also supported by FEDER through the COMPETE Program and by the FCT in the framework of the Strategic Project PEST-C/FIS/UI607/2013. P. Martins thanks FCT for the SFRH/BPD/96227/2013 grant.

\section{References}

[1] György I.: Conducting polymers: A new era in electrochemistry. Springer-Verlag, Berlin (2008).

[2] Hoppe H., Sariciftci N. S.: Organic solar cells: An overview. Journal of Materials Research, 19, 1924-1945 (2004).

DOI: $10.1557 / J M R .2004 .0252$

[3] Socher R., Krause B., Hermasch S., Wursche R., Pötschke P.: Electrical and thermal properties of polyamide 12 composites with hybrid fillers systems of multiwalled carbon nanotubes and carbon black. Composites Science and Technology, 71, 1053-1059 (2011). DOI: $10.1016 /$ j.compscitech.2011.03.004

[4] Popov C.: Nanostructured carbon materials. in 'Functional properties of nanostructured materials' (eds.: Kassing R., Petkov P., Kulish W., Popov C.) Springer, Dordrecht, 387-398 (2006).

DOI: $10.1007 / 1-4020-4594-834$

[5] Liu H., Hou L., Peng W., Zhang Q., Zhang X.: Fabrication and characterization of polyamide 6 -functionalized graphene nanocomposite fiber. Journal of Materials Science, 47, 8052-8060 (2012).

DOI: $10.1007 / \mathrm{s} 10853-012-6695-5$

[6] Steurer P., Wissert R., Thomann R., Mülhaupt R.: Functionalized graphenes and thermoplastic nanocomposites based upon expanded graphite oxide. Macromolecular Rapid Communications, 30, 316-327 (2009). DOI: $10.1002 /$ marc. 200800754

[7] Tsubokawa N.: Functionalization of carbon black by surface grafting of polymers. Progress in Polymer Science, 17, 417-470 (1992).

DOI: 10.1016/0079-6700(92)90021-P

[8] Mitchell C. A., Bahr J. L., Arepalli S., Tour J. M., Krishnamoorti R.: Dispersion of functionalized carbon nanotubes in polystyrene. Macromolecules, 35, 8825-8830 (2002).

DOI: $10.1021 / \mathrm{ma} 020890 \mathrm{y}$

[9] Bahr J. L., Tour J. M.: Covalent chemistry of single-wall carbon nanotubes. Journal of Materials Chemistry, 12, 1952-1958 (2002). DOI: $10.1039 / \mathrm{B} 201013 \mathrm{P}$
[10] Dyke C. A., Tour J. M.: Solvent-free functionalization of carbon nanotubes. Journal of the American Chemical Society, 125, 1156-1157 (2003).

DOI: $10.1021 / \mathrm{ja} 0289806$

[11] Socher R., Krause B., Müller M. T., Boldt R., Pötschke P.: The influence of matrix viscosity on MWCNT dispersion and electrical properties in different thermoplastic nanocomposites. Polymer, 53, 495-504 (2012). DOI: 10.1016/j.polymer.2011.12.019

[12] Bae W-S., Kwon O. J., Kim B. C., Chae D. W.: Effects of multi-walled carbon nanotubes on rheological and physical properties of polyamide-based thermoplastic elastomers. Korea-Australia Rheology Journal, 24, 221227 (2012).

DOI: $10.1007 / \mathrm{s} 13367-012-0027-9$

[13] Arboleda L., Ares A., Abad M. J., Ferreira A., Costa P., Lanceros-Mendez S.: Piezoresistive response of carbon nanotubes-polyamides composites processed by extrusion. Journal of Polymer Research, 20, 1-11 (2013). DOI: 10.1007/s10965-013-0326-y

[14] Krause B., Ritschel M., Täschner Ch., Oswald S., Gruner W., Leonhardt A., Pötschke P.: Comparison of nanotubes produced by fixed bed and aerosol-CVD methods and their electrical percolation behaviour in melt mixed polyamide 6.6 composites. Composites Science and Technology, 70, 151-160 (2010).

DOI: 10.1016/j.compscitech.2009.09.018

[15] Krause B., Pötschke P., Häußler L.: Influence of small scale melt mixing conditions on electrical resistivity of carbon nanotube-polyamide composites. Composites Science and Technology, 69, 1505-1515 (2009).

DOI: $10.1016 /$ j.compscitech.2008.07.007

[16] Ferreira T., Paiva M. C., Pontes A. J.: Dispersion of carbon nanotubes in polyamide 6 for microinjection moulding. Journal of Polymer Research, 20, 301-309 (2013). DOI: $10.1007 / \mathrm{s} 10965-013-0301-7$

[17] Leer C., van Hattum F. W. J., Gaspar-Cunha A., Carneiro O. S., Bernardo C. A.: Tailored shear extrusion of carbon nanofibre/polyamide composites and its effect on electrical percolation threshold. Plastics, Rubber and Composites, 35, 268-275 (2006).

DOI: $10.1179 / 174328906 X 146531$

[18] Coleman J. N., Khan U., Blau W. J., Gun'ko Y. K.: Small but strong: A review of the mechanical properties of carbon nanotube-polymer composites. Carbon, 44, 16241652 (2006). DOI: $10.1016 /$ j.carbon.2006.02.038

[19] Salmoria G. V., Paggi R. A., Lago A., Beal V. E.: Microstructural and mechanical characterization of PA12/ MWCNTs nanocomposite manufactured by selective laser sintering. Polymer Testing, 30, 611-615 (2011). DOI: $10.1016 /$ j.polymertesting.2011.04.007 
[20] Brosse A-C., Tencé-Girault S., Piccione P. M., Leibler L.: Effect of multi-walled carbon nanotubes on the lamellae morphology of polyamide-6. Polymer, 49, 4680-4686 (2008).

DOI: $10.1016 /$ j.polymer.2008.08.003

[21] Koysuren O., Yesil S., Bayram G.: Effect of composite preparation techniques on electrical and mechanical properties and morphology of nylon 6 based conductive polymer composites. Journal of Applied Polymer Science, 102, 2520-2526 (2006).

DOI: $10.1002 /$ app. 24654

[22] Pinto G., López-González C., Jimenez-Martín A.: Polymer composites prepared by compression molding of a mixture of carbon black and nylon 6 powder. Polymer Composites, 20, 804-808 (1999).

DOI: $10.1002 /$ pc. 10404

[23] Tchoudakov R., Breuer O., Narkis M., Siegmann A.: Conductive polymer blends with low carbon black loading: Polypropylene/polyamide. Polymer Engineering and Science, 36, 1336-1346 (1996).

DOI: $10.1002 /$ pen.10528

[24] Socher R., Krause B., Boldt R., Hermasch S., Wursche R. Pötschke P.: Melt mixed nano composites of PA12 with MWNTs: Influence of MWNT and matrix properties on macrodispersion and electrical properties. Composites Science and Technology, 71, 306-314 (2011). DOI: 10.1016/j.compscitech.2010.11.015

[25] Wu X., Qiu J., Liu P., Sakai E.: Preparation and characterization of polyamide composites with modified graphite powders. Journal of Polymer Research, 20, 284-291 (2013).

DOI: $10.1007 / \mathrm{s} 10965-013-0284-4$

[26] Kim S. R., Poostforush M., Kim J. H., Lee S. G.: Thermal diffusivity of in-situ exfoliated graphite intercalated compound/polyamide and graphite/polyamide composites. Express Polymer Letters, 6, 476-484 (2012).

DOI: $10.3144 /$ expresspolymlett.2012.50

[27] Gong L., Yin B., Li L-P., Yang M-B.: Nylon-6/graphene composites modified through polymeric modification of graphene. Composites Part B: Engineering, 73, 4956 (2015).

DOI: 10.1016/j.compositesb.2014.12.009

[28] Chou A., Böcking T., Singh N. K., Gooding J. J.: Demonstration of the importance of oxygenated species at the ends of carbon nanotubes for their favorable electrochemical properties. Chemical Communications, 7, 842-844 (2005).

DOI: $10.1039 / \mathrm{B} 415051 \mathrm{~A}$

[29] Lellinger D., Xu D., Ohneiser A., Skipa T., Alig I.: Influence of the injection moulding conditions on the in-line measured electrical conductivity of polymercarbon nanotube composites. Physica Status Solidi (B), 245, 2268-2271 (2008).

DOI: $10.1002 / p s s b .200879619$
[30] O’Neill A., Bakirtzis D., Dixon D.: Polyamide 6/ graphene composites: The effect of in situ polymerisation on the structure and properties of graphene oxide and reduced graphene oxide. European Polymer Journal, 59, 353-362 (2014).

DOI: $10.1016 /$ j.eurpolymj.2014.07.038

[31] Kelar K.: Polyamide 6 modified with fullerenes, prepared via anionic polymerization of $\varepsilon$-caprolactam. Polimery, 51, 415-424 (2006).

[32] Zuev V. V., Ivanova Y. G.: Mechanical and electrical properties of polyamide-6-based nanocomposites reinforced by fulleroid fillers. Polymer Engineering and Science, 52, 1206-1211 (2012).

DOI: $10.1002 /$ pen.22188

[33] Dencheva N., Gaspar H., Filonovich S., Lavrova O., Busani T., Bernardo G., Denchev Z.: Fullerene-modified polyamide 6 by in situ anionic polymerization in the presence of PCBM. Journal of Materials Science, 49, 4751-4764 (2014). DOI: $10.1007 / \mathrm{s} 10853-014-8174-7$

[34] Zuev V. V., Shlikov A. V.: Polyamide 12/fullerene C60 composites: Investigation on their mechanical and dielectric properties. Journal of Polymer Research, 19, 9925/1-9925/6 (2012).

DOI: $10.1007 / \mathrm{s} 10965-012-9925-2$

[35] Zuev V. V., Kostromin S. V., Shlykov A. V.: Mechanics of polymer nanocomposites modified with fulleroid nanofillers. Polymer Science Series A, 52, 532-536 (2010).

DOI: $10.1134 / \mathrm{S} 0965545 \mathrm{X} 10050081$

[36] Denchev Z., Dencheva N.: Polyamide microcapsules and method to produce the same. Portuguese Patent 107879, Portugal (2014)

[37] Dencheva N., Denchev Z., Lanceros-Méndez S., Sanz T. E.: One-step in situ synthesis of polyamide microcapsules with inorganic payload and their transformation into responsive thermoplastic composite materials. Macromolecular Materials and Engineering, in press (2015).

DOI: $10.1002 /$ mame.201500194

[38] Rusu Gh., Ueda K., Rusu E., Rusu M.: Polyamides from lactams by centrifugal molding via anionic ringopening polymerization. Polymer, 42, 5669-5678 (2001). DOI: 10.1016/S0032-3861(01)00059-3

[39] Roda J.: Polyamides. in 'Handbook of ring-opening polymerization' (eds.: Dubois P., Coulembier O., Raquez J-M.) Wiley-VCH, Weinheim, 165-196 (2009). DOI: $10.1002 / 9783527628407 . c h 7$

[40] Dan F., Vasiliu-Oprea C.: Anionic polymerization of caprolactam in organic media. Morphological aspects. Colloid and Polymer Science, 276, 483-495 (1998). DOI: $\underline{10.1007 / \mathrm{s} 003960050270}$ 
[41] Vasiliu-Oprea C., Dan F.: On the relation between synthesis parameters and morphology of anionic polycaproamide obtained in organic media. II. Influence of the $\mathrm{Na}\left[\mathrm{O}\left(\mathrm{CH}_{2}\right)_{2} \mathrm{OCH}_{3}\right]_{2} \mathrm{AIH}_{2} /$ aliphatic diisocyanates catalytic systems. Journal of Applied Polymer Science, 64, 2575-2583 (1997).

DOI: $10.1002 /($ SICI)1097-4628(19970627)64:13<2575 $\because$ AID-APP11>3.0.CO;2-Z

[42] Dan F., Vasiliu-Oprea C.: On the relationship between synthesis parameters and morphology of the anionic polycaproamide obtained in organic media. III. Macroporous powders obtained using $\mathrm{CO}_{2}$ and carbodiimides as activating compounds. Journal of Applied Polymer Science, 67, 231-243 (1998).

DOI: 10.1002/(SICI)1097-4628(19980110)67:2<231::

$$
\text { AID-APP5>3.0.CO;2-V }
$$

[43] Dencheva N., Denchev Z.: Clay distribution and crystalline structure evolution in polyamide $6 /$ montmorillonite composites prepared by activated anionic polymerization. Journal of Applied Polymer Science, 130, 1228-1238 (2013).

DOI: 10.1002/app.39274
[44] Dencheva N., Denchev Z., Pouzada A. S., Sampaio A. S., Rocha A. M.: Structure-properties relationship in single polymer composites based on polyamide 6 prepared by in-mold anionic polymerization. Journal of Materials Science, 48, 7260-7273 (2013).

DOI: $10.1007 / \mathrm{s} 10853-013-7546-8$

[45] Fornes T. D., Paul D. R.: Crystallization behavior of nylon 6 nanocomposites. Polymer, 44, 3945-3961 (2003).

DOI: $10.1016 / \mathrm{S} 0032-3861(03) 00344-6$

[46] Pesetskii S. S., Jurkowski B., Olkhov Y. A., Bogdanovich S. P., Koval V. N.: Influence of a cooling rate on a structure of PA6. European Polymer Journal, 41, 13801390 (2005).

DOI: 10.1016/j.eurpolymj.2004.12.009

[47] Dencheva N., Nunes T., Oliveira M. J., Denchev Z.: Microfibrillar composites based on polyamide/polyethylene blends. 1. Structure investigations in oriented and isotropic polyamide 6. Polymer, 46, 887-901 (2005). DOI: $10.1016 /$ j.polymer.2004.11.105 